\title{
Special issue editorial: synthetic biology, global health, and its global governance
}

\author{
Conor M. W. Douglas • Dirk Stemerding
}

Received: 9 July 2013/Accepted: 11 July 2013/Published online: 17 July 2013

(C) Springer Science+Business Media Dordrecht 2013

In 2009 the journal Systems and Synthetic Biology published a special issue outlining the societal aspects of synthetic biology (Schmidt 2009). Its contributions clearly showed the importance of contextualizing the hope and hype of synthetic biology (SynBio) with the ethical, legal, and social dynamics that might sometimes be seen to be outside of the conventional practice of science and technological development. Some papers that were included addressed biosafety and biosecurity issues pertinent to SynBio, as well as technical (i.e. Bedau et al. 2009; Danchin 2009) and governance (Kelle 2009; Weir and Selgelid 2009; Marliere 2009) strategies to mitigate such risks. Others presented media and public perceptions of SynBio (Cserer and Seiringer 2009; Kronberger et al. 2009; Pauwels 2009), while still others dealt with philosophical (Deplazes and Huppenbauer 2009), ethical (Rabinow and Bennett 2009), economic (Gaisser and Reiss 2009; Wellhausen and Mukunda 2009), and theological challenges (Dabrock 2009).

This Special Issue seeks to expand on this work in two ways. First it focuses on a particular set of SynBio applications and process as they relate to global health. Second, we seek here to expand the scope of 'societal aspects' to explore how they might play-out, and what their governance might look like, when placed in a global setting. Global health can be understood to operate with many of

C. M. W. Douglas · D. Stemerding

Technology Assessment, Rathenau Institute,

2593 HW The Hague, The Netherlands

C. M. W. Douglas ( $₫)$

Collaborations for Outcomes Research and Evaluation, Faculty

of Pharmaceutical Sciences, University of British Columbia,

2405 Wesbrook Mall, Vancouver, BC V6T 1Z3, Canada

e-mail: conor.douglas@ubc.ca the same objectives as public health in terms of promoting health and preventing disease; however, it stresses 'consideration of the health needs of the people of the whole planet above the concerns of particular nations' (Brown et al. 2006: 62) or particular publics. ${ }^{1}$ SynBio is positioned to address major global health issues through advanced vaccine development, diagnostics, drug synthesis, and the detection and remediation of environmental toxins.

Concerted attention to issues relating to SynBio, global health and global governance is well warranted at a time when considerable research funds have been made available by the Bill \& Melinda Gates Foundation under their 'Explorations' portfolio to 'Apply Synthetic Biology to Global Health Challenges' (see Rooke in this issue). What is more, the not-for-profit drug manufacturer OneWorld Health has begun its production and distribution of synthetic artemisinin, which has widely and loudly been heralded as considerable weapon in the global fight against malaria. $^{2}$ However, in the face of these developments challenges to the global governance of SynBio in a global health context continue. In 2012 debates ragged over whether or not to publish research on versions of avian H5N1 influenza virus 2012, ${ }^{3}$ and in the context of artemisinin, some have suggested that is not clear that

\footnotetext{
1 The World Health Organization (WHO) has defined public health as "the science and art of promoting health, preventing disease, and prolonging life through the organized efforts of society. It refers to all organized measures (whether public or private) to prevent disease, promote health, and prolong life of the population as a whole. Its activities aim to provide conditions in which people can be healthy and focuses on entire populations, not on individual patients or diseases. Thus, public health is concerned with the total system and not just the eradication of a particular disease (WHO 2005: 5).

${ }^{2}$ http://www.oneworldhealth.org/press_releases/view/pr_1305150097.

${ }^{3}$ http://www.nature.com/news/specials/mutantflu/index.html\#research.
} 
producing a drug of this sort in developed countries is the best way of either eradicating malaria in the long term or supporting sustainable development in the poorest countries' (Balmer and Martin 2008: 26).

With the aim to expand the discussion on societal aspects of SynBio in a global health context, and to explore what governance might entail for the global practice of SynBio, we held a workshop in The Hague in February of 2012 as a part of the SYBHEL project. ${ }^{4}$ We invited twentyseven participants from four constituencies of actors from around the world (e.g. China, India, Canada, United States of America, France, Spain, Switzerland, Belgium, Germany, England, Scotland, and the Netherlands). This included those with scientific and technical expertise in the practice of SynBio, and specifically those whose work seeks to address global health issues or whose practices are not bound by national borders or institutions (i.e. DIYbio). The second constituency were representatives from key international organizations that specialize in global health (i.e. WHO), global technological development and deployment (i.e. the OECD, the Health Impact Fund), and the global availability of biological parts for SynBio (i.e. the BioBricks Foundation). The third constituency were academics with expertise in the safe and responsible use of technologies for global health, and our fourth constituency were representatives from key regions that are involved in the development of SynBio for global health and/or the target of such interventions. Much of the contents of this Special Issue are based on contributions of these different groups of participants to this workshop.

This workshop intended to focus on questions concerning the global practice of SynBio on the one hand, and on the other hand the role that policy could play in fostering a relationship between SynBio and global health issues. Invited participants were asked to prepare papers, presentations, and comments on the following questions, which structured the workshop.

1. How can synthetic biology be used to address global health issues, relating for example to vaccine

\footnotetext{
4 The SYBHEL project's focus is on the potential ethical and legal implications of synthetic biology as it pertains to human health and wellbeing. The SYBHEL project is funded by the European Commission's science in society program, and is part of the seventh framework, ran from 2010 to 2012, and included five partners institutions from The University of Zurich, The University of Deusto, The Ratheneau Institute, and is coordinated by the Centre of Ethics in Medicine at the University of Bristol. The overall aim of the SYBHEL project is to examine the ethical implications of SynBio specifically for human health and well-being. In doing so the project examines philosophical and social understandings of life (including new human-like entities); appropriate methodology for bioethical analysis in SynBio for health; ethical issues arising in utilizing SynBio for health; regulatory and commercial aspects, and public policy over the application of SynBio to health.
}

development, drug synthesis, diagnostics and environmental monitoring for human health threats (including pandemics and bio-security threats)?

2. What are the conditions necessary to support the use of synthetic biology for addressing global health issues, like social and political conditions for SynBio research and innovation and take-up of its products in different regions of the world, technical and legal conditions relating to the access and availability of SynBio tools and biological parts, policy and regulatory conditions (including transnational collaboration), etc.?

3. How can policy ensure the safe, fair and responsible implementation of synthetic biology on a global level, taking into account environmental and health related bio-safety and bio-security issues, ethical questions (including questions of global justice) and a diversity of public and cultural perceptions of synthetic biology?

In addressing these questions, those with the scientific and technical expertise in the practice of SynBio outline how products or processes could be used towards the alleviation of global health burdens. In this Special Issue Jenny Rooke lays out the portfolio of projects on SynBio and global health that have recently been supported by the Bill \& Melinda Gates Foundation. Prerna Vohra and Gary Blakely describe their work that is funded under that program to develop a range of multivalent oral vaccines against the most common diarrhoea-causing bacteria (e.g. Escherichia coli, Shigella and Salmonella). Such work by Vohra and Blakely represents a very targeted approach through which a specific SynBio application might address a particular global health challenges. Next to this 'project approach' that targets a particular global health challenge with a specific SynBio product is the work James Carothers appearing in this issue, which sees the development of modelling and computer-aided design tools to facilitate a multi-use research platform. For him, such technological platforms make viable marketable products that can be 'reengineered to produce low cost global health materials' (Carothers this issue).

While there is much promise in both the targeted and multi-use approaches to SynBio for global health, Henk van den Belt and Aidan Hollis explore the dual problem of access and availability of such potential products. Van den Belt explores the relationship between SynBio, global health, intellectual property and access-to-knowledge frameworks; whereas Hollis outlines how the Health Impact Fund could be used to incentivize innovation in SynBio for global health, and to more fairly distribute the products of that innovation.

In other work appearing in this Special Issue Joy Zhang explores how specific trans-boundary features of SynBio actively disrupt established boundaries between professionals 
and amateurs, between scientific disciplines, and between geopolitical areas. For her, these trans-boundary features of SynBio both elicit and require new approaches to its global governance. This call is then addressed in part by the works of Betten, Roelofsen and Broerse, as well as Landrain, Meyer, Perez, Demouchy and Sussan, which both demonstrate how effective global health solutions require an opening of the SynBio innovation process to include end-users as well amateur communities. Landrain et al. examine the capacities of the Do-It-Yourself Biology movement to both practice SynBio around the global and participate in its (self) governance, and Betten et al. lay out a social science Interactive Learning and Action methodology that can be deployed throughout the SynBio innovation process to better address the needs and requirements of global health users.

The overall goal of this Special Issue is to increase our collective understanding of the practice of SynBio research and development for human health at the global level, and to better appreciate the role policy plays in enabling and/or constraining the responsible development of SynBio for global health. Our own contribution to the Special Issue works to summarize the dynamics between SynBio, global health, and global governance through the framework of 'responsible research and innovation' (Owen et al. 2012; von Schomberg 2013). In doing this we relate to the different contributions of the Special Issue, and synthetize them in a comprehensive review.

While all contributions here agree on the potentialities of SynBio to help address some major global health challenges, all would also readily acknowledge the importance of taking into account features that are not directly related to the technological configuration of products. For this a multidisciplinary approach is needed, and we hope that we have provided the foundation for that here.

\section{Contents of the special issue}

Rooke J (2013) Synthetic biology as a source of global health innovation. Syst Synth Biol

Vohra P, Blakely G (2013) Easing the global burden of diarrhoeal disease - Can synthetic biology help? Syst Synth Biol

Carothers J (2013) Design-driven, multi-use research agendas to enable applied synthetic biology for global health. Syst Synth Biol

van den Belt H (2013) Synthetic biology, patenting, health and global justice. Syst Synth Biol

Hollis A (2013) Synthetic biology: Ensuring the greatest global value. Syst Synth Biol

Zhang J (2013) The art of trans-boundary governance of synthetic biology. Syst Synth Biol
Landrain T, Meyer M, Perez AM, Demouchy M, Sussan R (2013) Do-It-Yourself Biology: Challenges and promises for an open science and technology movement. Syst Synth Biol

Betten AW, Roelofsen A, Broerse JEW (2013) Interactive Learning and Action: Realizing the promise of synthetic biology for global health. Syst Synth Biol

Douglas CWM, Stemerding D (2013) Governing synthetic biology for global health through responsible research and innovation. Syst Synth Biol

Acknowledgments This work was made possible through funding support from the SYBHEL project: Synthetic Biology for Human Health: Ethical and Legal Issues (SiS-2008-1.1.2.1-230401; a project funded under the European Commission's Science in Society Programme of Framework Programme 7). At the time this project was undertaken both authors were members of the Technology Assessment group at the Rathenau Institute in The Hague. We would like to acknowledge our SYBHEL project partners for their contribution and views. We would also like to thank the contributors to this Special Issue, the two-reviewers who provided helpful insights on earlier versions of this manuscript, and the editorial team at Springer. Most importantly we would like to acknowledge the participants from the Global Health Workshop held in The Hague in February of 2012 as a part of the SYBHEL project for their contributions, presentations, discussion. These include Wieke Betten, Garry Blakely, Rick Bleijs, Heather G. Bradshaw-Martin, Frans W.A. Brom, Alex Calladine, James Carothers, Michele Garfinkel, Daniel Gregorowius Aidan Hollis, Richard A. Johnson, Todd Kuiken, Thomas Landrain, Jeroen Maas, Stephen Maurer, Ruud ter Meulen, Patrick Middleton, Iñigo de Miguel, Lino Paula, Qui Renzong, Virgil Rerimassie, Ravi Srinivas, Sheryl Vanderpoel, Cécile J.B. van der Vlugt-Bergmans, and Robert C. Wells.

\section{References}

Balmer A, Martin P (2008) Synthetic biology: social and ethical challenges. An independent review commissioned by the Biotechnology and Biological Sciences Research Council (BBSRC) of the United Kingdom. Accessed October 25th, 2010. http:// www.bbsrc.ac.uk/organisation/policies/reviews/scientific-areas/ 0806-synthetic-biology.aspx

Bedau MA, Parke EC, Tangen U, Hantsche-Tangen B (2009) Social and ethical checkpoints for bottom-up synthetic biology, or protocells. Syst Synth Biol 3:65-75

Brown TM, Cueto M, Fee E (2006) The World Health Organization and the transition from "international" to "global" public health. Am J Public Health 96(1):62-72

Cserer A, Seiringer A (2009) Pictures of synthetic biology. Syst Synth Biol 3:25-35

Dabrock P (2009) Playing god? Synthetic biology as a theological and ethical challenge. Syst Synth Biol 3:47-54

Danchin A (2009) Information of the chassis and information of the program in synthetic cells. Syst Synth Biol 3:125-134

Deplazes A, Huppenbauer M (2009) Synthetic organisms and living machines: positioning the products of synthetic biology at the borderline between living and non-living matter. Syst Synth Biol 3:55-63

Gaisser S, Reiss T (2009) Shaping the science-industry-policy interface in synthetic biology. Syst Synth Biol 3:109-114

Kelle A (2009) Ensuring the security of synthetic biology - towards a 5P governance strategy. Syst Synth Biol 3:85-90 
Kronberger N, Holtz P, Kerbe W, Strasser E, Wagner W (2009) Communicating synthetic biology: from the lab via the media to the broader public. Syst Synth Biol 3:19-26

Marliere P (2009) The farther, the safer: a manifesto for securely navigating synthetic species away from the old living world. Syst Synth Biol 3:77-84

Owen R, Macnaghten P, Stilgoe J (2012) Responsible research and innovation: from science in society to science for society, with society. Sci Public Policy 39(6):751-760. doi:10.1093/scipol/scs093

Pauwels E (2009) Review of quantitative and qualitative studies on U.S. public perceptions of synthetic biology. Syst Synth Biol 3:37-46

Rabinow P, Bennett G (2009) Synthetic biology: ethical ramifications 2009. Syst Synth Biol 3:99-108
Schmidt M (2009) Special issue: societal aspects of synthetic biology. Syst Synth Biol 3:1-2

von Schomberg R (2013) A vision of responsible research and innovation. In: Owen R, Bessant J, Heintz M (eds) Responsible innovation: managing the responsible emergence of science and innovation in society. Wiley, Chichester, pp 51-74

Weir L, Selgelid MJ (2009) Professionalization as a governance strategy for synthetic biology. Syst Synth Biol 3:91-97

Wellhausen R, Mukunda G (2009) Aspects of the political economy of development and synthetic biology. Syst Synth Biol 3:115-123

World Health Organization (2005) Life science research: opportunities and risks for public health. Mapping the issues. Accessed 14 Dec 2011. http://whqlibdoc.who.int/hq/2005/WHO_CDS_CSR_ LYO_2005.20.pdf 